\title{
The MPA mouse breast cancer model: evidence for a role of progesterone receptors in breast cancer
}

\author{
Claudia Lanari, Caroline A Lamb, Victoria T Fabris, Luisa A Helguero, \\ Rocío Soldati, María Cecilia Bottino, Sebastián Giulianelli, \\ Juan Pablo Cerliani, Victoria Wargon and Alfredo Molinolo
}

Laboratory of Hormonal Carcinogenesis, Instituto de Biología y Medicina Experimental (IBYME)-Consejo Nacional de Investigaciones Científicas y Técnicas (CONICET), Vuelta de Obligado 2490 C1428ADN, Buenos Aires, CF, Argentina

(Correspondence should be addressed to A Molinolo who is now at Oral and Pharyngeal Cancer Branch, National Institute of Dental and Craniofacial Research, National Institutes of Health, Bethesda, Maryland 20892-4340, USA; Email: amolinol@mail.nih.gov)

( $L$ A Helguero is now at Department of Biosciences and Nutrition, Karolinska Institutet, Novum, SE-141 57 Huddinge, Sweden)

\begin{abstract}
More than $60 \%$ of all breast neoplasias are ductal carcinomas expressing estrogen (ER) and progesterone receptors (PR). By contrast, most of the spontaneous, chemically or mouse mammary tumor virus induced tumors, as well as tumors arising in genetically modified mice do not express hormone receptors. We developed a model of breast cancer in which the administration of medroxyprogesterone acetate to BALB/c female mice induces mammary ductal carcinomas with a mean latency of 52 weeks and an incidence of about $80 \%$. These tumors are hormone-dependent (HD), metastatic, express both ER and PR, and are maintained by syngeneic transplants. The model has been further refined to include mammary carcinomas that evolve through different stages of hormone dependence, as well as several hormone-responsive cell lines. In this review, we describe the main features of this tumor model, highlighting the role of PR as a trigger of key signaling pathways mediating tumor growth. In addition, we discuss the relevance of this model in comparison with other presently used breast cancer models pointing out its advantages and limitations and how, this model may be suitable to unravel key questions in breast cancer.
\end{abstract}

Endocrine-Related Cancer (2009) 16 333-350

\section{Introduction}

Breast cancer is the most frequent cancer in women (23\% of all cancers), and it ranks second overall when both sexes are considered together (Parkin et al. 2005). Most tumors are ductal infiltrating carcinomas expressing estrogen (ER) and progesterone receptors (PR). The majority of the genetically modified mouse breast cancer models as well as most spontaneous, chemically or mouse mammary tumor virus (MMTV)-induced mammary tumors in mice do not express ER and PR, or if they do (some MMTV models), they are pregnancydependent (Kordon 2008). One of the few exceptions is the medroxyprogesterone acetate (MPA)-breast cancer model. More than 20 years ago, we developed an experimental model in mice, in which MPA induced mammary carcinomas that expressed high levels of ER and PR. The aim of this review is to assemble all the results of the last 20 years to better understand the possibilities and limitations of this model for the further understanding of breast cancer.

At the beginning of the 1980's, we became interested in the clinical observation that progestins may block growth in the benign but invasive fibroblastic proliferations known as desmoid tumors (Lanari et al. 1978, Lanari 1983). In trying to find a mouse model where we could reproduce these results, we decided to investigate the inhibitory effects of progestins on foreign body tumorigenesis in BALB/c mice. In this specific type of tumorigenesis, the subcutaneous (s.c.) 
implantation of a glass cylinder in mice results in the formation of a thick fibrous capsule surrounding the cylinder. Within $\sim 9$ months, fibrosarcomas would develop from that capsule, with an incidence of $79 \%$ (Lanari et al. 1986b). To evaluate the effects of progestins on fibrosarcoma growth, we decided to use MPA rather than progesterone $(\mathrm{Pg})$, because MPA compound was easier to handle, as it was available in a depot delivery form and it did not have to be injected on daily basis. We showed that in BALB/c mice treated with $40 \mathrm{mg}$ MPA depot s.c., every 2-3 months (four doses), the number of foreign body fibrosarcomas that developed was significantly lower than in the untreated controls (Lanari et al. 1986b). Unexpectedly, the few MPA-treated female mice remaining at the end of the experiment developed mammary carcinomas. Two follow-up studies performed using exclusively female mice confirmed this carcinogenic effect, yielding multiple mammary carcinomas with a mean latency of 1 year and an average incidence of about $80 \%$ (Lanari et al. 1986a, Kordon et al. 1994). The fact that progestins could induce mammary neoplasias was rather counter-intuitive, as the consensus at that time (and for many years to come) was that, estrogens were the proliferative/carcinogenic hormones, whereas $\mathrm{Pg}$ exerted mainly differentiating effects, thus counteracting the stimulatory properties of estrogens. However, there was already evidence that challenged this dogma. Pg or MPA administered in certain schedules of carcinogenesis protocols increased mammary tumor incidence in rats (Young 1961, Jabara 1967, Jabara et al. 1973), in mice carrying endogenous MMTV (van Nie 1964, Sluyser \& Van Nie 1974), and in cats and dogs (Hernandez et al. 1975, Concannon et al. 1981). In addition, Pg (Watson et al. 1979) and MPA (Formelli et al. 1985) stimulated the growth of the MXT transplantable mouse tumors.

The carcinogenic effect reported for MPA was also supported by later studies in rats, cats, dogs, and mice (Russo et al. 1989, Misdorp 1991, Ohi \& Yoshida 1992, Pazos et al. 1992, Aldaz et al. 1996, Goepfert et al. 2000, Benakanakere et al. 2006). The findings of the WHI Study (WHI 2002) and the Million Women Study (Beral 2003), showing increased breast cancer in estrogens-plus-progestin-treated women, further highlighted the risk associated with chronic progestin administration in humans. By 1999, a Working Group at the International Agency for Research on Cancer, World Health Organization (IARC) concluded that there was sufficient evidence in experimental animals for the carcinogenicity of MPA (limited evidence for carcinogenicity in dogs had been the previous evaluation in 1979; IARC Working Group 1979,
1999), and moved MPA to Group 2B (possibly carcinogenic to humans). In 2005, the IARC Working Group, on the basis of several studies that included postmenopausal therapy with estrogens plus MPA, considered that there was sufficient evidence in humans for carcinogenicity of combined estrogenprogestogen menopausal therapy in the breast, and moved it from Group 2B to Group 1 (carcinogenic to humans; IARC Working Group 2007). Various reports have also highlighted the proliferative role of progestins on breast cancer and have been recently reviewed (Moore 2004, Aupperlee et al. 2005, Kariagina et al. 2008).

\section{MPA-induced carcinogenesis}

\section{Mammary carcinomas}

In the first study, in which we reported the carcinogenic effects of MPA, the tumors were histologically classified as B adenocarcinomas according to Dunn's classification (Sass \& Dunn 1979). As most of the neoplasias, as well as the preneoplastic lesions, were similar to the human ductal counterparts, we re-classified all tumors following the histological criteria used for the human disease. Accordingly, $68 \%$ of the tumors were ductal carcinomas and the other $32 \%$ were lobular carcinomas. Using a different protocol in which MPA was given as a s.c. $40 \mathrm{mg}$ silastic pellet that was replaced by a $20 \mathrm{mg}$ pellet 6 months later, MPA also proved to be carcinogenic, with an incidence of $58 \%$, and, in this case, the ratio of ductal to lobular carcinomas was even higher, with $89 \%$ being ductal (Kordon et al. 1993). Ductal hyperplasias or carcinomas in situ were detected in most animals that did not develop carcinomas. In a few cases, lymph node and lung metastases were observed. Detached groups of tumor cells were also found within veins in different organs during histopathological evaluation of complete autopsies. All ductal mammary carcinomas expressed high levels of ER and PR, as well as prolactin receptors as evaluated by ligand binding techniques. Prolactin and epidermal growth factor (EGF) receptors were detectable in purified membrane fractions (Molinolo et al. 1987, Lanari et al. 1989). The low percentage of lobular carcinomas arising from MPA-treated animals, were very similar in morphology to those originating in other experimental models (IARC 1994, Seely \& Boorman 1999, Greaves 2007), as well as to spontaneous carcinomas occasionally found in aging, multiparous BALB/c and other mice strains (Rehm \& Liebelt 1996 and personal observation). Similarly, to what happens in these models, the lobular tumors may 
express when evaluated by binding techniques, low levels of ER and PR. However, and unlike what happens with the ductal carcinomas, the expression of ER and PR is lost, if transplanted subcutaneously, after a few passages (Kordon et al. 1993, 1994). The nomenclature 'lobular' was given to these tumors because their preneoplastic lesions mimicked those of human lobular carcinomas, which are characterized by an increase in the number of alveolar structures with progressive enlargement due to intra-alveolar growth, as well as because they would occasionally infiltrate the stroma in linear arrays of malignant cells, the 'Indian files' images also seen in human lobular cancer, but it is quite possible that they represent a different biological entity.

\section{Other effects of MPA}

MPA-treatment was also associated with the early development of endometrial glandular cystic hyperplasias and/or deciduomas regardless of the presence of mammary carcinomas (Lanari et al. 1986a, Molinolo et al. 1987). MPA also induced the differentiation of the granular convoluted tubules in the female's submaxillary salivary glands (Kordon et al. 1994, Montero Girard et al. 2007), leading to an increase in gland size. This had already been shown by Bullock et al. (1975) as part of the androgenic effect of MPA. The hypertrophy was associated with an increase in EGF synthesis and an increase in serum EGF levels. $\mathrm{BALB} / \mathrm{c}$ or $\mathrm{C} 57 \mathrm{BL} / 6$ mice treated with MPA increased their body weight (Pazos et al. 1998, Montero Girard et al. 2007). The administration of MPA to mice, 7 or 90 days before immunization with sheep red blood cells, significantly enhanced both primary and secondary antibody responses, without affecting delayed-type hypersensitivity (Vermeulen et al. 2001). Additionally, we demonstrated that MPA decreased the incidence of leukemias, while it did not affect the incidence of lung adenomas in $N$-methyl- $N$-nitrosourea (MNU)-treated mice (Pazos et al. 2001).

\section{MPA versus progesterone}

Pg administration also induced mammary carcinomas when given as $40 \mathrm{mg}$ pellets replaced by $20 \mathrm{mg}$ pellets after 6 months, although the incidence was lower than that obtained with MPA (28 vs 58\%; Kordon et al. 1993). Only $28.5 \%$ of the Pg-induced carcinomas were ductal; while the rest showed lobular differentiation, according to the histological criteria mentioned above. In the uterus, Pg induced a microglandular hyperplasia; cystic lesions as well as deciduomas were consistently absent.

\section{Correlation between histology and hormone dependence}

To evaluate hormone dependence (HD), MPA or Pg-induced carcinomas were transplanted into MPAtreated or untreated mice. The tumors that did not grow during the first 2 months in untreated animals were considered $\mathrm{HD}$, or more specifically progestin-dependent (PD), while those that did grow were designated hormone-independent (HI), or progestin-independent (PI). Out of 48 carcinomas in which histology and HD were recorded, 15 were lobular and HI, 32 were ductal and HD, and only one ductal tumor was HI. Histological evaluation was performed blinded to the HD status, and it proved to be a good predictor of HD in this model (Kordon et al. 1993, 1994).

\section{Strain specificity}

To evaluate the strain-specificity for the carcinogenic effect of MPA, we tested $\mathrm{C} 3 \mathrm{H}$ and C57BL/6 female mice using the standard protocol of MPA depot. The incidence of mammary carcinomas was significantly different between MPA-treated $\mathrm{C} 3 \mathrm{H}$ mice and untreated controls (32 vs $16 \%, P<0.05$ ). C57BL/6 MPA-treated female mice did not develop mammary carcinomas. Moreover, MPA and Pg induced morphological changes in the mammary glands of C57BL/6 different from those seen in BALB/c mice (Montero Girard et al. 2007). Similar results have recently been shown by Aupperlee et al. (2009). Along this line, we also demonstrated that the expression of ER $\alpha$ and of the A isoform of the PR (PR-A) was lower in virgin $\mathrm{C} 57 \mathrm{BL} / 6$ mice than in $\mathrm{BALB} / \mathrm{c}$ mice. Interestingly, when epithelial mammary cells from both strains were transplanted into cleared mammary fat pads of the same immunocompromised mouse, both morphological and receptor expression differences were abolished, thus reinforcing the role of the microenvironment in mediating epithelial hormone responsiveness. These results highlight the role of the altered expression of susceptibility/resistance genes in both, anomalous hormone responsiveness and breast cancer.

\section{Effects of sialoadenectomy or ovariectomy in MPA-induced carcinogenesis}

The initial observation that female mice treated with MPA developed salivary glands hypertrophy led us to look for factors derived from such glands that may have played a role in mammary carcinogenesis. As previously stated, MPA induces through androgenic actions, the differentiation of convoluted granular 
tubules that are responsible for the synthesis and secretion of several growth factors and EGF among them (Bullock et al. 1975). We showed that in BALB/c mice sialoadenectomy ( $\mathrm{Sx}$ ) lowered the incidence of MPA-induced mammary carcinomas and that this was associated with diminished branching of the mammary glands (Molinolo et al. 1996). Inoculation with EGF was able to restore and even increase branching (Molinolo et al. 1998). Sx also affected the induction of MNU-induced carcinomas in MPA-treated mice (Molinolo et al. 1996). In the rat, EGF has also been demonstrated to participate in MNU-induced mammary carcinogenesis (Chou et al. 1999).

In ovariectomized (ovx) mice, the incidence of MPA-induced mammary carcinomas was significantly lower than in sham-operated animals, and the same was true for MNU + MPA-induced mammary tumors (unpublished observations, E Kordon, P Pazos, C Lanari \& AA Molinolo). In ovx mice, the lack of estrogen levels high enough to induce the expression of physiologically relevant quantities of PR in the mammary gland, may explain the lesser carcinogenicity of MPA. The fact that some tumors did develop, in spite of the absence of a significant estrogenicity, may be explained by the fact that MPA induces the synthesis and secretion of salivary glands' EGF, a factor that has been shown to exert estrogenic effects (Bunone et al. 1996).

\section{MPA-induced mammary carcinomas: tumor transplants}

\section{Hormone dependence}

Progestin-induced mammary carcinomas were subcutaneously transplanted into the inguinal flank of female $\mathrm{BALB} / \mathrm{c}$ mice treated or non-treated with MPA. If the tumors grew only during the first 2 months in treated mice, they were considered PD or HD.

\section{HD growth}

Ovariectomy delayed tumor growth in both MPAtreated and in untreated animals. In untreated ovx mice, the tumors grew very slowly after more than 6 months, which was probably due to adrenal hormones, since no growth was observed in ovx/adrenalectomized animals (Kordon et al. 1990, Montecchia et al. 1999a).

When tumors were transplanted into ovx animals, $\mathrm{Pg}$ was able to stimulate HD growth nearly as well as MPA, while dihydrotestosterone (DHT) exerted a slight proliferative effect (Kordon et al. 1990). It has been demonstrated that the administration of 8-Cl-cAMP (Actis et al. 1995), TNFa (Rivas et al. 2008) or fibroblast growth factor (FGF-2) (Giulianelli et al. 2008) can also mimic the MPA effect in vivo. Although, most of the HD tumors studied showed similar patterns of hormone dependence, the degree of this dependency varied among HD tumors. The tumors with the highest degree of hormone dependence would stop growing and even regress after hormone withdrawal (Simian et al. 2006), while others would stop growing or continue to grow very slowly. When transplanted into intact immunocompromised mice, they showed the same MPA requirement (Kordon et al. 1994).

\section{HI growth}

Occasionally, these HD tumors start to grow in untreated animals (Fig. 1). At this point, we suggest that this tumor has become HI. When this happens, the original HD tumor is recovered from frozen samples from early passages, while the HI tumor is maintained by syngeneic transplantation in untreated BALB/c mice. These HI tumors grow in both intact and ovx mice and some of them grow faster in non-ovx animals.

\section{Treatment responsiveness and tumor regression}

The administration of $17 \beta$-estradiol $\left(\mathrm{E}_{2} ; 5\right.$ or $0.5 \mathrm{mg}$ silastic pellets) exerted a clear inhibitory effect in s.c. implanted tumors and in primary cell cultures (Lamb et al. 2003). It is interesting to note, as previously mentioned that ovx in these animals is associated with a significant reduction of MPA carcinogenicity. It seems that physiological estrogen levels are required to induce PR expression in the mammary gland, which in turn may be necessary for tumor induction. However, in the established tumors, the sustained pharmacological serum concentrations achieved through the external $E_{2}$ administration results in a potent inhibitory signal.

Interestingly, and as opposed to what happens in most of the traditional mouse models, pregnancy inhibits R-PI tumor growth (Bustuoabad et al. 2002). It is possible that the increased $\mathrm{E}_{2}$ levels observed in pregnancy might be counteracting the proliferative effect of Pg. The administration of three different antiprogestins, mifepristone (RU-486), onapristone (ZK 98299) or ZK 230211 (Hoffmann \& Sommer 2005), in daily s.c. doses of $6-12 \mathrm{mg} / \mathrm{kg}$ body weight, also inhibited tumor growth or induced complete tumor regressions in most of the ductal $\mathrm{HI}$ variants growing in BALB/c (Kordon et al. 1991, Montecchia et al. 1999a, Vanzulli et al. 2002, Wargon et al. 2008) or nude mice (unpublished observations, R Soldati, A Vanzulli, AA Molinolo \& C Lanari). The in vivo administration of PR antisense oligodeoxynucleotides (asPR) 


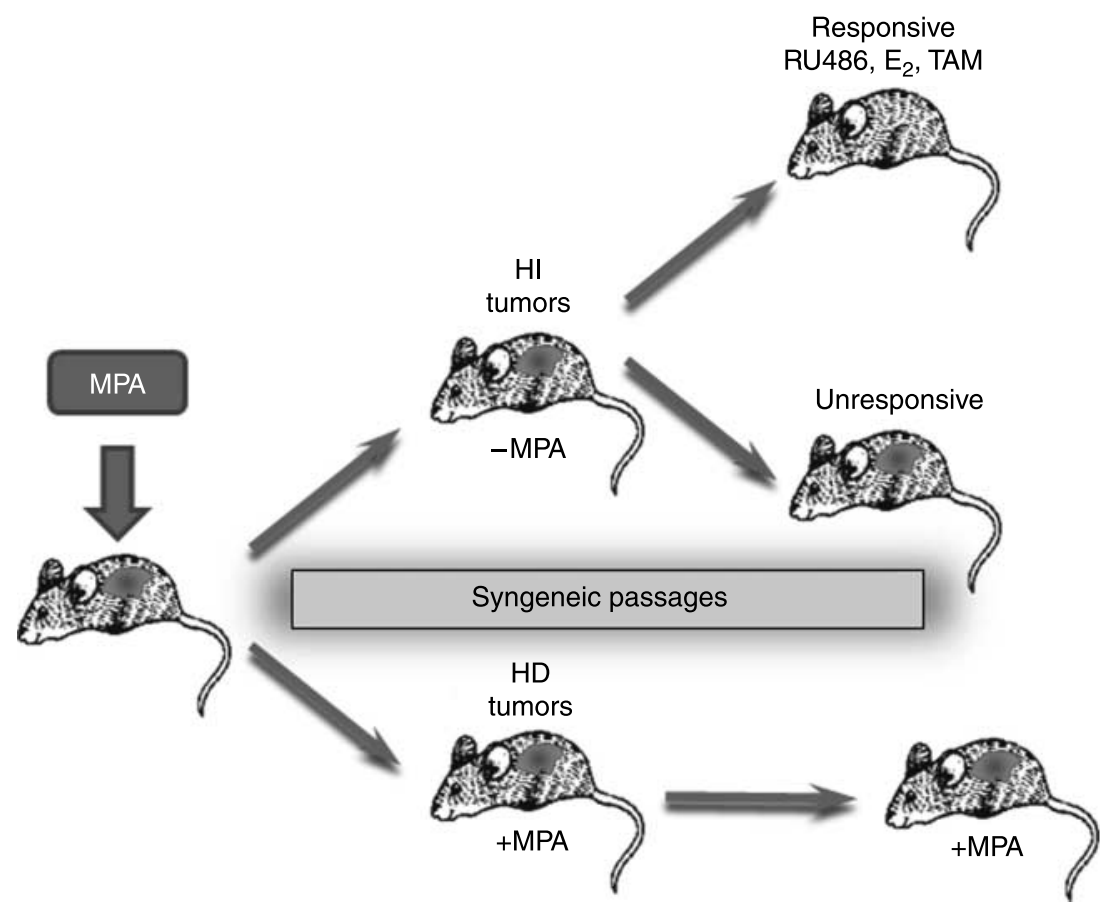

Figure 1 Tumor transplants and generation of tumors. The continuous administration of MPA to female BALB/c mice induces HD mammary carcinomas, which are maintained by syngeneic transplants into MPA-treated mice. Two mice are left untreated to control $\mathrm{HD}$. Occasionally, tumors start to grow in untreated mice and, as a result, a $\mathrm{HI}$ tumor is established. These tumors grow even in the absence of MPA. Some of those HI tumors are inhibited by the treatment with antiprogestins (RU486), estrogens ( $\left.\mathrm{E}_{2}\right)$ or tamoxifen (TAM; responsive $\mathrm{HI}$ : R-PI), and other HI tumors are unresponsive to the hormonal treatment (unresponsive HI tumors: UR-PI).

induced a transient inhibition of tumor growth supporting the key role of PR in tumor growth (Lamb et al. 2005b). The antiandrogens hydroxyflutamide and flutamide had no effect (Montecchia et al. 1999a).

Since some HI or PI variants did not respond to estrogens or antiprogestins, we had to re-classify PI tumors as responsive (R-PI) and unresponsive (UR-PI) tumors (Helguero et al. 2003b; Table 1). The four UR-PI tumor variants may be considered as de novo

Table 1 MPA-induced mammary carcinomas

\begin{tabular}{llll}
\hline & \multicolumn{3}{c}{ Hormone independent } \\
\cline { 2 - 4 } $\begin{array}{l}\text { Hormone } \\
\text { dependent }\end{array}$ & Responsive & Acquired & De novo \\
\cline { 2 - 4 } C4-HD & $\mathrm{C} 4-\mathrm{HI}$ & $\mathrm{C} 4-\mathrm{HIR}^{\mathrm{a}}$ & $\mathrm{C} 4-2-\mathrm{HI}$ \\
$\downarrow$ & $\mathrm{C} 4-\mathrm{HI}$ & & \\
$\mathrm{CC} 4-\mathrm{HD}^{\mathrm{b}}$ & $\mathrm{CC} 4-3-\mathrm{HI}$ & & $\mathrm{C}-\mathrm{HI}$ \\
$\mathrm{C} 7-\mathrm{HD}$ & $\mathrm{C} 7-2-\mathrm{HI}^{\mathrm{a}}$ & BET & $32-\mathrm{HI}$ \\
$32-\mathrm{HD}$ & $32-2-\mathrm{HI}$ & & \\
$48-\mathrm{HD}$ & $48-\mathrm{HI}$ & & $59-\mathrm{HI}$ \\
$59-\mathrm{HD}$ & $59-2-\mathrm{HI}$ & $59-2-\mathrm{HIR}$ & \\
\hline
\end{tabular}

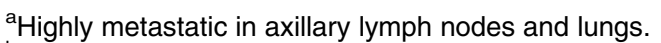
${ }^{b}$ Primary cultures of C4-HD were inoculated subcutaneously and maintained by serial transplantation. resistant tumors and were resistant to both estrogens and antiprogestins (Figs 1 and 2). The specificity of the RU486 and MPA effects was assayed using different transplantable tumor models, such as a syngeneic lymphoma, LB, and a methylcholantrene-induced fibrosarcoma (Bustuoabad et al. 2002), and no significant differences between treated mice and controls were observed (unpublished observations, C Lamb, V Fabris, C Lanari \& AA Molinolo).

Tamoxifen (daily s.c. injections of $5 \mathrm{mg} / \mathrm{kg}$ body weight) induced an inhibition of growth in R-PI and in HD tumors growing either in the presence or in the absence of MPA (Lamb et al. 2003). In this model, tamoxifen behaves as an estrogenic agonist, albeit with lower efficacy than estrogens. Raloxifene was only assayed in HD tumors; it had no effects in tumor growth in vivo $(12.5 \mathrm{mg} / \mathrm{kg}$ daily doses). Doxorubicin, administered as pegylated liposomes (Doxopeg, Laboratorios Raffo, Argentina; 9 or $18 \mathrm{mg} / \mathrm{kg}$ once a week), induced significant growth inhibition (unpublished observations, R Soldati, I Luthy, L Colombo, AA Molinolo \& C Lanari).

The effect of $\alpha(2)$-adrenoceptor agonists and antagonists has also been studied in our model, as stress may be an important modulator of breast 

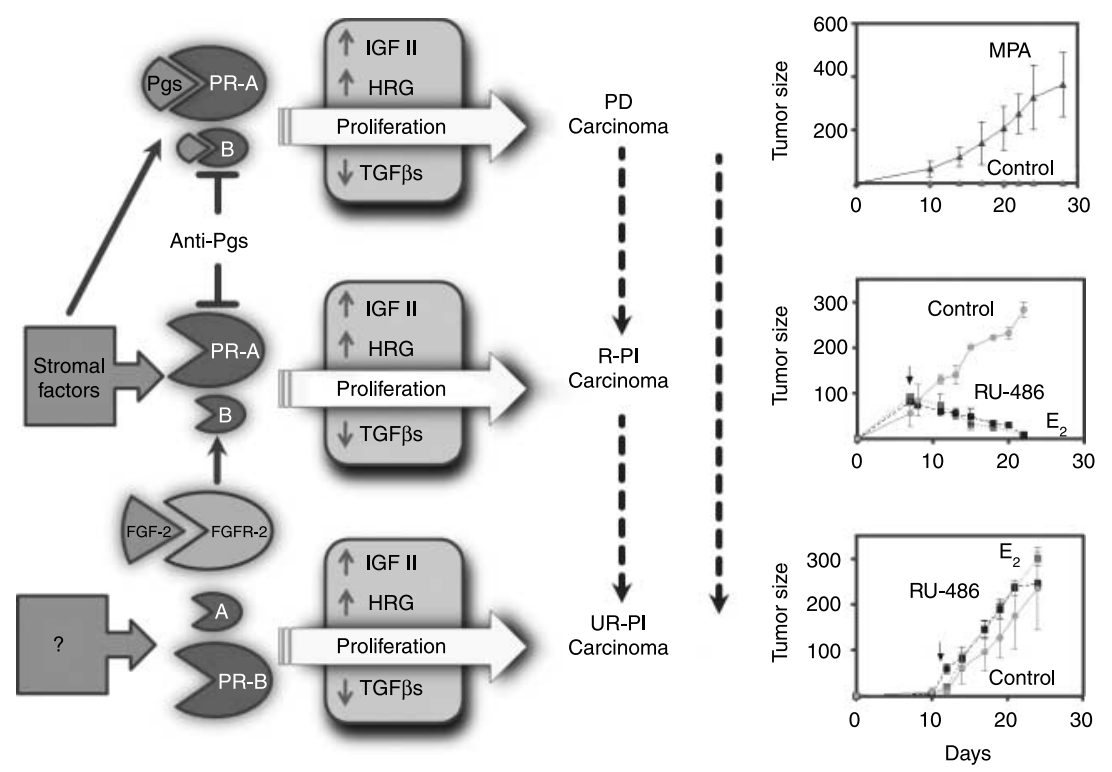

Figure 2 Working hypothesis. PR play a key role regulating tumor growth. In HD (PD) carcinomas, MPA or Pg interact with PR inducing a proliferative state characterized by the presence of high levels of stimulating growth factors such as IGF-II and HRG and low levels of inhibitory factors such as TGF $\beta$ s. If tumors are able to grow without exogenous hormone supply they are considered $\mathrm{HI}$ or PI. In these tumors, we have hypothesized that paracrine stromal factors mimic Pg signaling, and therefore, the tumors have a growth pattern similar to PD tumors growing with MPA. FGF-2 is one of the stromal paracrine growth factors inducing PR activation through binding with FGFR-2, its cognate receptor, in the epithelial cells. Therefore, the blockage of PR will induce effects similar to progestin removal in the PD tumors: cytostasis and apoptosis. These tumors are responsive progestin-independent tumors (R-PI) and, as PD tumors, they have higher expression of PR-A than PR-B. However, in some PI tumors, PR inhibition with antiprogestins does not inhibit tumor growth (UR-PI). These tumors still express PR but they have a different pattern of isoform expression, as observed by western blots: higher expression of PR-B than PR-A.

cancer growth. Clonidine significantly enhanced tumor growth while the antagonists yohimbine and rauwolscine, completely reversed the effects of clonidine. Rauwolscine alone diminished tumor growth significantly, behaving as a reverse agonist (Bruzzone et al. 2008).

Cytostasis, apoptosis (Vanzulli et al. 2002) or differentiation (Wargon et al. 2008) are the hallmarks of tumor regression. The morphological changes of tissue remodeling were preceded by an early increase in $\mathrm{p} 53, \mathrm{p} 21$, and $\mathrm{p} 27$ expression. ER and PR expression were down-regulated $48 \mathrm{~h}$ after the onset of tumor regression (Vanzulli et al. 2002, 2005). Concomitantly, with the increase in apoptosis, there was also an increase in tissue remodeling (Simian et al. 2006). Interestingly, an increased expression of the CDK inhibitors p21 and p27 was also observed in primary cultures of C4-HD cells treated with TGF $\beta 1$ (Salatino et al. 2001), suggesting that antiprogestins and estrogens may increase TGF $\beta$ activity. In T47D human breast cancer cells, antiprogestins have also been shown to induced an increase in TGF $\beta 1$ expression (Dannecker et al. 1996). The chronology of events that lead to tumor regression, as well as the mechanisms by which $\mathrm{E}_{2}$ and antiprogestins converge to induce tumor regression, are now actively being studied in our laboratory.

\section{Estrogen and progesterone receptors}

Two different binding sites were observed for PR, one with a high capacity and with an affinity similar to the standard $K_{\mathrm{d}}$ described for PR $\left(K_{\mathrm{d}}: 9.2 \mathrm{nM}\right.$; $Q=376 \mathrm{fmol} / \mathrm{mg}$ protein; Bayard et al. 1977), and a second low-capacity, high-affinity binding site with a $K_{\mathrm{d}}$ of $43 \mathrm{pM}$ (Helguero et al. 2003a). ER were also detected by binding techniques with a standard $K_{\mathrm{d}}$ of $1.5 \mathrm{nM}$.

All the studied ductal tumors expressed ER $\alpha$ and ER $\beta$ as determined by western blotting. Both PR-A $(83 \mathrm{kDa})$ and PR-B (115 kDa) were detected in HD and R-PI tumors. PR-A expression was always higher than PR-B (Helguero et al. 2003b, Wargon et al. 2008) and MPA down-regulated both PR isoforms (Helguero et al. 2003b). In UR-PI tumor samples, PR-A expression was almost undetectable (Helguero et al. 2003b, Wargon et al. 2008). In addition, RNase protection assays did not reveal any differences in total mRNA between R-PI and UR-PI tumors. The western blot data were corroborated by immunohistochemistry, using antibodies specific for PR-B and PR-A 
(Aupperlee et al. 2005, Wargon et al. 2008). In addition, in immunofluorescence studies, we observed that both $\mathrm{PR}$ isoforms were co-expressed in the same cells.

The UR-PI tumors may be considered as de novo or constitutively resistant tumors. Using selective pressure, we have also generated estrogen- and antiprogestin-resistant tumors. We have shown that acquired estrogen resistance (Montecchia et al. 1999b) or acquired antiprogestin resistance (Wargon et al. 2008), are reversible phenomena. These acquired antiprogestin-resistant variants had, as de novo resistant tumors, lower levels of PR-A than PR-B, suggesting that the $\mathrm{PR}$ isoform ratio is predictive of antiprogestin responsiveness (Wargon et al. 2008).

\section{Growth factor receptors and ligands}

Similar levels of insulin-like growth factor 1 (IGF-I) and IGF-1 receptors, detected by RNase protection and by radio receptor assays, were found in $\mathrm{HI}$ and $\mathrm{HD}$ tumors in the presence or absence of MPA. IGF-II, on the other hand, was up-regulated by MPA and was highly expressed in HI tumors (Elizalde et al. 1998). Man 6P/type II IGF receptors were down-regulated by MPA. The blockage of IGF-1 receptors by antisense oligodeoxynucleotides in vivo induced a delay in tumor growth that does not seem to be mediated by PR (Salatino et al. 2004), suggesting that IGF-I signaling is downstream of PR.

The expression of heregulin (HRG), c-erbB2, and c-erbB3 was up-regulated by MPA in HD tumors, reaching levels similar to those observed in the HI tumor variants. c-erbB4 expression that was not regulated by MPA, was similar in HD and HI tumors (Balana et al. 1999, 2001). TGFßs 1, 2, and 3 were down-regulated by MPA in HD tumors, and their expression levels were lower in the HI variants. TGF $\beta$ $1 \mathrm{R}$ and 2 were present in HD ductal tumors, but only TGF $\beta$ 1R was significantly detected in the HI variants (Elizalde et al. 1995, Viegas et al. 1999). FGFR-2 was also highly expressed in HI tumors and up-regulated by MPA in the HD tumors (Giulianelli et al. 2008).

All these results indicate that R-PI tumor variants are biologically similar to their respective parental tumors, reinforcing the hypothesis that in R-PI tumors, PR are activated by signals that mimic the progestin effect. We hypothesize that the increase in growth stimulatory factors and the decrease in inhibitory factors are intrinsic to the proliferative state of the tumors, and that they may act in concert downstream of PR, triggering mitotic and antiapoptotic signals (Fig. 2).

\section{Trp53 mutations and cytogenetic analysis}

Five different HD tumors as well as some of their derived HI variants, and two lobular tumors were studied by PCR-SSCP and sequenced for Trp53 mutations. C4-HD, and most of its $\mathrm{HI}$ variants had the same point mutation, a $\mathrm{C}-\mathrm{G}$ change at position 456 in exon 5, representing a serine to arginine mutation at codon 152, within the DNA binding site (S152R; Fabris et al. 2005). p53 is one of the most frequently mutated proteins in human cancer (Bourdon 2007). This transcription factor is a key regulator of cell cycle and apoptosis, which is activated in response to different stresses, genotoxic as well as not genotoxic, and modulates the transcription of several genes ( $\mathrm{p} 21, \mathrm{mdm} 2$, GDD45, bax). p53 is also involved in DNA repair and centrosome stability. The untimely activation, inactivation or otherwise deregulation of any of these processes could arguably contribute to the development and maintenance of the malignant phenotype. Between 20 and $35 \%$ of human breast tumors present in mutations p53, occurring principally on the DNA binding domain (Lacroix et al. 2006).

The functionality of the C4-HD p53 mutations was assessed in studies using its derived MC4 cell lines, which carry the same mutations. The exposure of these cells to UVB does not induce an increase in p21.

A nearly diploid chromosome number $(2 n=40)$ was found in three of the five HD tumors, while numbers in the triploid to tetraploid range were observed in the other two HD tumors (Fabris et al. 2005). Some HI tumors were diploid, while most of them were aneuploid (8/12 tumors). The most frequent alterations found in $\mathrm{HD}$ and $\mathrm{HI}$ tumors were gains of chromosomes 3,4 , and 6 , and losses of chromosomes 16 and X. Chromosomes 4 and 7 were involved in translocations in three of the four tumor families studied. We evaluated the evolution of the karyotype in the transition to $\mathrm{HI}$ and have demonstrated that HI may be acquired without changes in ploidy, suggesting that the increase in ploidy observed in many tumors is favored by successive transplantation. In our model, all diploid tumors responded to hormone treatment $\left(\mathrm{E}_{2}\right.$ or antiprogestins), while aneuploid tumors were either responsive or not (Fabris et al. 2005).

Mutations in the $p 53$ gene are frequently associated to aneuploidy and chromosome instability. However, the fact that C4-HD tumor, unlike its HI counterparts, maintains a rather stable karyotype during in vivo passages may be indicating that other factors in concert with p53 may drive chromosome instability. 


\section{Metastatic ability}

All ductal carcinomas assayed gave rise to metastases in lymph nodes and lungs. Some of these tumors are specially suited for this type of studies as they develop metastases early, usually within 2 months of transplantation (Table 1). In general, lymph node metastases tend to be histologically more differentiated than the s.c. implant, a fact that is apparently unrelated to the selection of a specific cell subpopulation. When lymph nodes metastases are s.c. transplanted into syngeneic animals, the histology reverts to that of the originally primary tumor, displaying now the less differentiated phenotype, a fact that underscores once again the significant role of the microenvironment in regulating the specific tumor features. These results are in agreement with recent findings showing that in humans, tumor cells in lymph node metastases have a $\mathrm{CD} 24+$, luminal phenotype (Shipitsin et al. 2007). Hormone receptors are still expressed in both lymph node and lung metastases (Vanzulli et al. 2005), at levels similar to those of the primary tumor, and antiprogestins and estrogens induced regression of the metastasis. This phenomenon is associated with increased cell differentiation, increased expression of p21 and p27, and down-regulation of ER and PR (Vanzulli et al. 2005). It is worth pointing out that this is one of the very few models of lymph nodes metastases in murine mammary carcinomas (Vargo-Gogola \& Rosen 2007).

\section{In vitro studies}

\section{Primary cultures}

To obtain epithelial or fibroblastic enriched cultures, we use standard protocols (Pandis et al. 1992), with slight modifications (Dran et al. 1995). To test the effects of steroids or growth factors, cells are always grown with DMEM F12-HAM in the presence of 1-5\% steroid-stripped serum.

\section{Epithelial cells}

MPA- and Pg-stimulated cell proliferation at concentrations as low as $10^{-12} \mathrm{M}$. DHT had no effect and dexamethasone was stimulatory at concentrations higher than $10 \mathrm{nM}$ (Dran et al. 1995). $\mathrm{E}_{2}$ exerted an inhibitory effect even at low concentrations (Dran et al. 1995, Lamb et al. 2003). The anti-progestins, RU486, and ZK 98299 (Lamb et al. 1999), exerted a striking inhibitory effect, while the antiandrogen hydroxyflutamide had no effect. The inhibitory effect of RU486 was observed at concentrations as low as $10 \mathrm{nM}$. It has been reported that $10 \mathrm{nM}$ RU486 does not bind to the glucocorticoid receptors in T47Dco cells (Horwitz 1985), thus supporting the role of $P R$ in mediating cell growth. All effects were specific for C4-HD, since no changes were observed in primary cultures from a MPA-induced lobular carcinoma or in a spontaneous tumor that arose in a multiparous BALB/c mouse (Dran et al. 1995). The anti-estrogen fulvestrant (ICI 182780) as well as the selective estrogen receptor modulators, tamoxifen, and raloxifene, all inhibited cell proliferation. In the presence of MPA, fulvestrant and tamoxifen were inhibitory and raloxifene stimulated MPA-induced cell proliferation. As for the growth factors, EGF, IGF-I or IGF-II, they exerted almost no stimulatory effect when administered alone (Elizalde et al. 1998, Molinolo et al. 1998); however, IGF-I increased MPA-induced cell proliferation. On the other hand, FGFs and HRG exerted a stimulatory effect on MPA-treated or -untreated cells (Lanari et al. 1997, Balana et al. 1999, Lamb et al. 1999). TGF $\beta$ 1-3 were all inhibitory (Viegas et al. 1999). Interestingly, serum from MPA-treated ovx mice stimulated cell proliferation to levels higher than that from ovx mice, to which MPA was added exogenously, indicating that other serum factors in addition to MPA are participating in tumor growth (Lamb et al. 1999). These results are in agreement with data reported in T47D-YB cells in which progestins, in addition to inducing cell proliferation, also stimulate the production of soluble factors that would be responsible for the sustained MAPK signaling leading to cell growth (Faivre \& Lange 2007).

\section{Fibroblasts}

Carcinoma-associated fibroblasts (CAFs) were unresponsive to progestins, estrogens or androgens. Antihormones at concentrations of $10^{-6} \mathrm{M}$ induced minor inhibitory effects, except for RU486, which slightly stimulated cell proliferation. On the other hand, all growth factors tested, including the TGF $\beta$ s, were stimulatory for fibroblasts (Lanari et al. 1997). CAF from HI tumors expressed higher levels of FGF-2 and hepatocyte growth factor than CAFs from HD tumors (Giulianelli et al. 2008), leading to the idea that CAFs participate in HI growth (Fig. 2).

\section{Cell lines}

We have developed several cell lines from C4-HD (Lanari et al. 2001) and C7-2-HI tumors (Efeyan et al. 2004). The most interesting feature of these cell lines is that, unlike most murine mammary cancer cell lines, they retain ER and PR expression, although at levels lower than those of the primary cultures from the same 
tumors (Lanari et al. 2001, Aliaga et al. 2004). These cell lines showed different degrees of hormone responsiveness in vitro, and both estrogens and progestins were stimulatory. Anti-progestins stimulated cell growth at low concentrations, but they inhibited cell proliferation at concentrations higher than $100 \mathrm{nM}$. Estrogens, unlike what happens in the parental tumors (both in vivo and in primary cultures), where they behave as inhibitory agents, may stimulate cell proliferation. Even though preliminary data of our laboratory suggest that this difference is not related to the expression of specific ER $\alpha$ or ER $\beta$ isoforms, we cannot rule out a role for the ER $\alpha$ splice variant ER 36 (Wang et al. 2006). This variant has been demonstrated to be involved in cell proliferation, and the fact that it may be active only in the cell lines remains to be explored. The complete absence of the modulating influence of stromal ECM in the cell lines, as opposed to what happens in transplants may also help to explain the differential estrogen response. Others have reported differences in hormone responsiveness between in vitro and in vivo settings; MCF-7 cells are stimulated in vitro by estrogens, whereas in vivo the presence of the hormone is an absolute requirement, as they simply do not grow without estrogen supplementation in immunocompromised animals (Shafie 1980). The reason of this difference remains still unknown.

Two cell lines, a cloned epithelial tumor cell line, MC4-L4E, and a stromal non-tumorigenic cell line, named MC4-L4F, were also developed from the parental tumor C4-HD. Both express ER $\alpha$ and low levels of PR, show increased epithelial cell growth and an increase in PR expression when co-cultured under starvation conditions. These characteristics provide an interesting tool to study stromal-parenchymal interactions (Lamb et al. 2005a).

\section{PR, key player mediating cell proliferation}

In 1993, we found that RU486 was able to completely inhibit MPA-induced and steroid stripped seruminduced cell proliferation in HD cells, suggesting that PRs were playing a pivotal role in mediating this effect. At that time, the concepts of 'ligand-independent activation' and 'crosstalk' were gaining acceptance and Edwards et al. (1993) had suggested that PR could be activated by cAMP analogues. FGFs were the only ones of a series of growth factors tested that stimulated cell proliferation like MPA (Lamb et al. 1999). Using different anti-progestins and asPR, we demonstrated that FGFs stimulated cell proliferation via the PR pathway (Lanari et al. 1997). Later, Labriola et al. (2003) used the same cells and HRG instead of
FGFs to confirm a crosstalk between MAPK and PR in the MPA tumor model.

All the results obtained using the HD tumors suggested that HI tumors might have ligand-independent activated PR (Montecchia et al. 1999a, Lamb et al. 2005b). Anti-progestins induced complete tumor regressions and asPR ( $1 \mathrm{mg}$ every $12 \mathrm{~h}$ for 5 days) were also inhibitory. We measured the Pg concentration in both HD and HI tumors and found no differences (0.1-0.5 ng/ml; RIA). The remaining unanswered question was what activated PR in HI tumors. Our working hypothesis, as depicted in Fig. 2, was that PD tumors were progestin- and PR-dependent while R-PI tumors were only PR-dependent. We hypothesized that stromal factors, such as FGF-2, might be responsible for activating PR. The fact that (a) isolated epithelial cells from C4-HI cultures were as MPA- or FGF-2-dependent as epithelial cells from C4-HD cultures and (b) CAF from HI tumors were much more stimulatory than CAF from HD tumors, led us to propose that factor/s secreted by CAF from HI tumors may be participating in the HI phenotype and FGF-2 was a likely candidate. Indeed, FGF-2 does activate PR in C4-HI cells; a neutralizing FGF-2 antibody and the genetic or pharmacological blockade of FGFR-2 inhibit CAF-induced epithelial cell proliferation and PR activation (Giulianelli et al. 2008). This in vitro data, together with the in vivo data demonstrates that FGF-2 stimulated C4-HD growth and that the FGFR inhibitor (PD 173074) decreased HI growth, which underscores the role of $\mathrm{CAF}$ in $\mathrm{HI}$ tumor growth.

\section{Estrogen and antiprogestin in breast cancer treatment}

Estrogens were extensively used for the treatment of breast cancer prior to tamoxifen (Carter et al. 1977) and have been experimentally shown to induce tumor regression in the T61 human breast tumor transplant model in nude mice (Brunner et al. 1996). Cell lines overexpressing PKC $\alpha$ (Chisamore et al. 2001, Lin et al. 2006) and cells which become addicted to tamoxifen (Yao et al. 2000) are inhibited by estrogens. The possibility of exploiting these findings in breast cancer treatment has been recently reviewed (Jordan 2008).

Antiprogestins, on the other hand, have been shown to inhibit experimental mammary cancer. In breast cancer patients, positive responses with RU486 have been reported (Klijn et al. 1989). In this series, most side effects were related to the antiglucocorticoid activity of RU486, thus illustrating the need of pure 
antiprogestins (Klijn et al. 2000). Both RU486 and ZK 98299 were also shown to inhibit DMBA and MNUinduced mammary carcinomas in rats, as well as the MXT mouse tumors (Michna et al. 1989a,b, Schneider et al. 1989). Apoptosis and tumor differentiation were the mechanisms related with antiprogestin-induced tumor regression (Michna et al. 1992a,b, Vollmer et al. 1992). Differentiation was also induced in normal mammary glands (Li et al. 1995). The T61 human xenograft model, inhibited with estrogens as mentioned above, was also inhibited by ZK 98299, although in this case $\mathrm{E}_{2}$ priming was necessary to increase the expression of PR (Schneider et al. 1992). The authors hypothesized that the inhibitory effect of ZK 98299 should involve other mechanisms in addition to its antiprogestin activity. In our model, antiprogestins only induced significant growth inhibition in PR-positive tumors. In other models, using s.c. transplantable tumors, only slight differences were seen (Check et al. 2007). It is possible, as NK have been shown to be modulated by progestins (Arruvito et al. 2008), that an immune-mediated mechanism may contribute to their efficacy (Check et al. 2007). Several groups have reported that the combination of antiprogestins and antiestrogens in breast cancer treatment was more efficacious than single drug treatments (Klijn et al. 2000). Experimentally, in MCF-7 cells transplanted in estrogen-treated nude mice, the simultaneous administration of tamoxifen and antiprogestins induced complete tumor inhibition. Monotherapy with tamoxifen or antiprogestins induced only a retardation of growth (el Etreby \& Liang 1998, el Etreby et al. 1998). Similarly, the Pg-induced stimulation of T47D xenotransplants was suppressed by RU486 (Liang et al. 2007). These authors highlighted the proangiogenic role of MPA in breast cancer growth (Liang \& Hyder 2005). Noteworthy, Poole et al. (2006) have recently reported that RU486 administration to BRCA1/p53-null female mice inhibits the generation of DMBA-induced tumors, as well as mammary gland branching.

A series of breast cancer clinical trials with different antiprogestins have already been reviewed (Klijn et al. 1994, 1996, Shi et al. 1994). Even though ZK 98299 showed less antiglucocorticoid activity than RU486, it had to be withdrawn from the market because of liver toxicity (Klijn et al. 2000). Interestingly, when PR-B is activated by high levels of cAMP, RU486 acts as an agonist (Horwitz 1992, Baulieu 1997), thus stimulating cell proliferation. Because of this, there has been certain resistance to the use of these agents for breast cancer treatment. The novel antiprogestin ZK 230211 has lower antiglucocorticoid activity, and it does not induce agonistic effects in the presence of protein kinase A activators (Fuhrmann et al. 2000). Accrual is now ongoing for breast cancer patients for a phase II clinical trial (http://clinicaltrials.gov/ct2/show/ NCT00555919) using this drug. An even newer development is CDB-4124 and its putative metabolite CDB-2914, an antiprogestin with almost no antiglucocorticoid effects (Attardi et al. 2002, 2004, Wiehle et al. 2007).

\section{MPA-induced mammary carcinomas versus human breast cancer and other breast cancer models}

Present classifications of human breast cancers are based on their specific molecular profiles, rather than exclusively on their histological features (Hu et al. 2006). The PI or HI tumors of the MPA breast cancer model share many features with the luminal breast cancers: a) most tumors are of ductal histology; b) they are invasive and metastatic; c) they are hormone responsive; d) express ER and PR; and e) respond to chemotherapy (Table 2). Some of them respond to estrogens, tamoxifen, and antiprogestins. Similarly, some human breast cancers are responsive to tamoxifen and to estrogens. Interestingly, 30\% of established human breast cancer cell lines are ER-positive and they are stimulated by $E_{2}$. Several cell lines derived from the murine tumors of this model are also stimulated by $\mathrm{E}_{2}$.

\section{Mouse breast cancer models expressing steroid receptors}

The MXT carcinoma (Watson et al. 1979) was one of the earliest $\mathrm{ER}(+), \mathrm{PR}(+)$-described tumors. This tumor model has been used for evaluating of the effects of chemotherapeutic agents and different hormones, as well as to test the effects of antiprogestins (Darro et al. 2005). Other strains such as GR or BALB/c, carrying the MMTV, develop pregnancy-dependent tumors that regress after parturition (Kordon 2008). Tumors of these models have a pattern of hormoneresponsiveness completely different than most of the human breast carcinomas and they have been useful to study MMTV-activated oncogenes (Kordon 2008). The M05 BALB/c mouse tumor (Simian et al. 2008) arising spontaneously in a virgin female mouse, looks promising for hormonal studies, as tumor growth is inhibited with tamoxifen. The fact that this is the only one tumor, rather than a set of neoplastic proliferations, limits data validation. 
Table 2 Comparison between MPA-induced mammary carcinomas and human breast cancer

\section{MPA-induced mammary carcinomas}

Ductal carcinomas

Metastasis in lymph nodes and lung

$\operatorname{ER}(+), \operatorname{PR}(+)$

c-erbB2 $(+)$

p53 mutations in $20 \%$ of the tumors

Responsive to endocrine treatment

Clinical progression to hormone resistance

May regress completely by estrogen treatment

May be responsive to tamoxifen treatment

May regress completely by antiprogestin treatment

Responsive to doxorubicin

Cell lines are stimulated by $\mathrm{E}_{2}$

Progestins may stimulate tumor growth
Human breast cancer

$78 \%$ are ductal carcinomas; Glass et al. (2007)

Metastasis in lymph nodes and bone

$70 \%$ are $\mathrm{ER}(+), \mathrm{PR}(+)$

$20-25 \%$ are c-erbB2 $(+)$

p53 mutations in $20 \%$ of the tumors

Responsive to endocrine treatment

Clinical progression to hormone resistance

Estrogens have been successfully used for treatment in a group of patients

Different degrees of tamoxifen sensitivity

There has been some responsiveness to antiprogestin treatment in few trials

Responsive to doxorubicin

$30 \%$ of the derived cell lines are stimulated by $E_{2}$

Progestins may inhibit or stimulate tumor growth

\section{Xenografts in immunodeficient animals}

These are the most common models used to evaluate hormone-related breast cancer and most of the studies come from a rather limited set of cell lines inoculated in nude or SCID mice, including MCF-7, T47D, ZR-75. None of these cell lines originate metastasis in vivo unless genetically modified, except for the recently developed IBH-4, IBH-6, and IBH-7 (Bruzzone et al. 2009). The fact that the human cells are growing in an immunodeficient mouse environment constitute obvious shortcomings of these approaches. New models have been developed in which human fibroblasts were transplanted together with the neoplastic cells, thus creating a humanized environment, although the possible role of the immune system has not been yet properly addressed (Proia \& Kuperwasser 2006).

\section{Genetic engineered mouse models}

As recently reviewed (Vargo-Gogola \& Rosen 2007, Allred \& Medina 2008), there are no mouse engineered models in which the induced mammary tumors give rise to metastasis either in lymph node, brain or bone. In addition, there are no consistent reports on metastatic carcinomas responding to hormone therapy, even though models are available in which hyperplastic growths retain ER and PR expression, such as a fraction of tumors arising in mammary glands from p53 null mice transplanted into in a BALB/c background. In other models, epithelial cells are genetically manipulated to express $\mathrm{ER} \alpha$, transformed in vitro and then transplanted into mice, resulting in metastatic estrogen-responsive tumors (Duss et al. 2007).

\section{Summary and future directions}

Our studies underscore the carcinogenic and proliferative effects of MPA in the BALB/c mammary gland. They also indicate that the effects of MPA on the mammary gland are different from those of Pg. Both compounds have different carcinogenic effects, although both substances are able to stimulate the growth of already established tumors. Using this model, we have also given a hierarchical role to the PR, as mediators of tumor growth. Progestin-independent growth was inhibited by antiprogestins and asPR suggesting that these tumors, although progestin independent, were still PR dependent for their growth. The essential role of PR on the mammary gland became evident when Lydon et al. (1999) developed the PR knockout mouse and showed absence of mammary gland development or mammary tumor development in the absence of PR. The present therapy for endocrine-related breast cancer involves targeting ER or its ligands (Jordan \& Brodie 2007). Since an important role for ER is the induction of $P R$ expression, it seems reasonable to expect that antiprogestin therapy may be a beneficial treatment approach for endocrine-responsive breast cancer. It seems possible that the use of therapies aimed to block the PR, either together or alternated with anti-estrogens or aromatase inhibitors may delay the onset of hormone resistance. An imbalance of PR isoform expression has been reported in breast cancers (Mote et al. 2002) and tumors with higher PR-A/PR-B ratios are those which have been shown to exhibit a poorer response to tamoxifen treatment (Hopp et al. 2004). Interestingly, in the MPA-induced tumor model, tumors with these features would respond to 
antiprogestins, and it may also be possible to identify similar subpopulations of human cancers.

The MPA breast cancer model has limitations and advantages. As a limitation common to other transplant models, neoplastic cells are injected into otherwise normal organisms in which the predisposing risk factors are absent. Also, the fact that most of the genetic engineered mice had been developed in backgrounds other than BALB/c, limits the possible use of these tumors in genetically modified backgrounds.

Probably, the most important advantages are that the model is established in immunocompetent animals and that the ductal mammary carcinomas originated express ER and PR, are hormone-responsive, and metastasize to lymph nodes and lungs. Even though we have not yet used this model for intracranial or intrafemoral tumor cells injections, this possibility remains to be exploited.

Established and highly characterized cell lines of human origin such as MCF-7, T47D, MDA-231, and others have become a standard tool in the study of different aspects of breast cancer. Each represent, however, what is found in a single individual, and recreating specific aspects such as hormone responsiveness/resistance usually require complex gene manipulations. We believe that the MPA model, with the ample array of carcinomas of different biological behavior, may better represent through their natural genetic drift, the interindividual variations and the heterogeneity found among tumors. It is also worth pointing that, regardless of this natural genetic drift and the acquisition by some of the tumors of specific mutations, hormone responsiveness remains closely similar in the whole family of parental tumors; most of them are still strongly hormone responsive. This allows the testing of different approaches to understand the acquisition of $\mathrm{HI}$ and hormone resistance, one of the most challenging areas of breast cancer research.

The possibility to work with primary cultures in $2 \mathrm{D}$ and 3D, separating CAF from epithelial cells or co-culturing both populations has allowed us to investigate the role of tumor stroma on the acquisition of HI. In addition, undergoing studies profiling stroma from different $\mathrm{HD}$ and $\mathrm{HI}$ tumors growing in vivo will provide further information to understand the role of stroma in $\mathrm{HI}$ and resistance. It has recently been hypothesized that progestins may induce the selection of stem cell in patients with breast cancer (Horwitz \& Sartorius 2008), which may open up the possibility of investigating this hypothesis in the MPA-induced breast cancer model, and to investigate, whether we have targeted the stem cell population in tumors that have experienced complete clinical regression.
Standard concepts on general carcinogenesis fail to fit the natural history of hormone-induced mammary carcinomas, as effective proof of a specific mutagenic initiation hit is still lacking. Moreover, present knowledge points to the fact that the progression of these cancers seems to be driven by epigenetic events and signaling pathway cross-talks, rather than by specific genetic changes. A revisit to the general cancer paradigm is in this case, long overdue. The MPAinduced mammary carcinomas may be the ideal environment in which to test these highly relevant questions, as it represents a hormone-induced, hormone-driven cancer that progresses strongly associated with the EGF signaling axis in the preneoplastic stages, becomes addicted to the PR pathway, and closely interacts with other relevant paths such as that of the FGFR.

\section{Declaration of interest}

The authors declare that there is no conflict of interest that could be perceived as prejudicing the impartiality of the research reported.

\section{Funding}

This project has been supported by grants from the Sales Foundation, and also by grants from SECYT, CONICET, and the Roemmers Foundation. Dr Molinolo is supported by the Intramural Research Program of the Institute of Dental and Craniofacial Research, National Institutes of Health, Bethesda, MD, USA.

\section{Acknowledgements}

We wish to thank Dr Christiane Dosne Pasqualini for being the mentor of this model and Dr Silvio Gutkind (NIDCR, $\mathrm{NIH}$ ) for critically reading the manuscript and for helpful suggestions. We also thank Miss Julieta Bolado and Dr María Alicia Gorostiaga for excellent technical support, Gador Laboratories (Buenos Aires) for providing MPA and to Raffo Laboratories (Buenos Aires) for the doxorubicin liposomes. We also thank Bayer Schering Pharma AG, Berlin for the ZK 230211, Pfizer Global Pharmaceuticals for the PD 173074 and to Zeneca Pharmaceuticals England for kindly providing fulvestrant.

\section{References}

Actis AM, Caruso SP \& Levin E 1995 Opposite effect of a cAMP analogue on tumoral growth related to hormone dependence of a murine mammary tumor. Cancer Letters 96 81-85.

Aldaz CM, Liao QY, LaBate M \& Johnston DA 1996

Medroxyprogesterone acetate accelerates the 
development and increases the incidence of mouse mammary tumors induced by dimethylbenzanthracene. Carcinogenesis 17 2069-2072.

Aliaga A, Rousseau JA, Ouellette R, Cadorette J, van Lier JE, Lecomte R \& Benard F 2004 Breast cancer models to study the expression of estrogen receptors with small animal PET imaging. Nuclear Medicine and Biology 31 761-770.

Allred DC \& Medina D 2008 The relevance of mouse models to understanding the development and progression of human breast cancer. Journal of Mammary Gland Biology and Neoplasia 13 279-288.

Arruvito L, Giulianelli S, Flores AC, Paladino N, Barboza M, Lanari C \& Fainboim L 2008 NK cells expressing a progesterone receptor are susceptible to progesteroneinduced apoptosis. Journal of Immunology 180 57465753.

Attardi BJ, Burgenson J, Hild SA, Reel JR \& Blye RP 2002 CDB-4124 and its putative monodemethylated metabolite, CDB-4453, are potent antiprogestins with reduced antiglucocorticoid activity: in vitro comparison to mifepristone and CDB-2914. Molecular and Cellular Endocrinology 188 111-123.

Attardi BJ, Burgenson J, Hild SA \& Reel JR 2004 In vitro antiprogestational/antiglucocorticoid activity and progestin and glucocorticoid receptor binding of the putative metabolites and synthetic derivatives of CDB-2914, CDB-4124, and mifepristone. Journal of Steroid Biochemistry and Molecular Biology 88 277-288.

Aupperlee MD, Smith KT, Kariagina A \& Haslam SZ 2005 Progesterone receptor isoforms A and B: temporal and spatial differences in expression during murine mammary gland development. Endocrinology 146 3577-3588.

Aupperlee MD, Drolet AA, Durairaj S, Wang W, Schwartz RC \& Haslam SZ 2009 Strain-specific differences in the mechanisms of progesterone regulation of murine mammary gland development. Endocrinology 150 1485-1494.

Balana ME, Lupu R, Labriola L, Charreau EH \& Elizalde PV 1999 Interactions between progestins and heregulin (HRG) signaling pathways: HRG acts as mediator of progestins proliferative effects in mouse mammary adenocarcinomas. Oncogene 18 6370-6379.

Balana ME, Labriola L, Salatino M, Movsichoff F, Peters G, Charreau EH \& Elizalde PV 2001 Activation of ErbB-2 via a hierarchical interaction between ErbB-2 and type I insulin-like growth factor receptor in mammary tumor cells. Oncogene 20 34-47.

Baulieu EE 1997 RU 486 (mifepristone). A short overview of its mechanisms of action and clinical uses at the end of 1996. Annals of the New York Academy of Sciences $\mathbf{8 2 8}$ 47-58.

Bayard F, Kreitmann B \& Derache B 1977 Measurement of the progesterone receptors in normal and neoplastic tissues. In Progesterone Receptors in Normal and Neoplastic Tissues, Eds WL McGuire, E Baulieu \& JP Raynaud. New York: Raven Press.
Benakanakere I, Besch-Williford C, Schnell J, Brandt S, Ellersieck MR, Molinolo A \& Hyder SM 2006 Natural and synthetic progestins accelerate 7,12-dimethylben$\mathrm{z}$ [a]anthracene-initiated mammary tumors and increase angiogenesis in Sprague-Dawley rats. Clinical Cancer Research 12 4062-4071.

Beral V 2003 Breast cancer and hormone-replacement therapy in the Million Women Study. Lancet 362 419-427.

Bourdon JC 2007 p53 and its isoforms in cancer. British Journal of Cancer 97 277-282.

Brunner N, Spang-Thomsen M \& Cullen K 1996 The T61 human breast cancer xenograft: an experimental model of estrogen therapy of breast cancer. Breast Cancer Research and Treatment 39 87-92.

Bruzzone A, Pinero CP, Castillo LF, Sarappa MG, Rojas P, Lanari C \& Luthy IA 2008 Alpha2-adrenoceptor action on cell proliferation and mammary tumour growth in mice. British Journal of Pharmacology 155 494-504.

Bruzzone A, Vanzulli S, Giulianelli S, Lanari C \& Luthy I 2009 Novel human breast cancer cell lines IBH-4, IBH-6 and IBH-7 growing in nude mice. Journal of Cellular Physiology 219 477-484.

Bullock LP, Barthe PL, Mowszowicz I, Orth DN \& Bardin CW 1975 The effect of progestins on submaxillary gland epidermal growth factor: demonstration of androgenic, synandrogenic and antiandrogenic actions. Endocrinology 97 189-195.

Bunone G, Briand PA, Miksicek RJ \& Picard D 1996 Activation of the unliganded estrogen receptor by EGF involves the MAP kinase pathway and direct phosphorylation. EMBO Journal 15 2174-2183.

Bustuoabad OD, di Gianni PD, Franco M, Kordon EC, Vanzulli SI, Meiss RP, Grion LC, Diaz GS, Nosetto SH, Hockl P et al. 2002 Embryonal mass and hormoneassociated effects of pregnancy inducing a differential growth of four murine tumors. Oncology Reports $\mathbf{1 3}$ 147-160.

Carter AC, Sedransk N, Kelley RM, Ansfield FJ, Ravdin RG, Talley RW \& Potter NR 1977 Diethylstilbestrol: recommended dosages for different categories of breast cancer patients. Report of the Cooperative Breast Cancer Group. Journal of the American Medical Association 237 2079-2085.

Check JH, Sansoucie L, Chern J, Amadi N, Srivastava M \& Larece K 2007 Evidence that progesterone receptor antagonists may help in the treatment of a variety of cancers by locally suppressing natural killer cell activity. Clinical and Experimental Obstetrics and Gynecology 34 207-211.

Chisamore MJ, Ahmed Y, Bentrem DJ, Jordan VC \& Tonetti DA 2001 Novel antitumor effect of estradiol in athymic mice injected with a T47D breast cancer cell line overexpressing protein kinase Calpha. Clinical Cancer Research 7 3156-3165.

Chou YC, Guzman RC, Swanson SM, Yang J, Lui HM, Wu V \& Nandi S 1999 Induction of mammary carcinomas by $N$-methyl- $N$-nitrosourea in ovariectomized rats treated with epidermal growth factor. Carcinogenesis 20 677-684. 
Concannon PW, Spraker TR, Casey HW \& Hansel W 1981 Gross and histopathologic effects of medroxyprogesterone acetate and progesterone on the mammary glands of adult beagle bitches. Fertility and Sterility 36 373-387.

Dannecker C, Possinger K \& Classen S 1996 Induction of TGF-beta by an antiprogestin in the human breast cancer cell line T-47D. Annals of Oncology 7 391-395.

Darro F, Decaestecker C, Gaussin JF, Mortier S, Van Ginckel R \& Kiss R 2005 Are syngeneic mouse tumor models still valuable experimental models in the field of anti-cancer drug discovery? International Journal of Oncology 27 607-616.

Dran G, Luthy IA, Molinolo AA, Montecchia F, Charreau EH, Pasqualini CD \& Lanari C 1995 Effect of medroxyprogesterone acetate (MPA) and serum factors on cell proliferation in primary cultures of an MPA-induced mammary adenocarcinoma. Breast Cancer Research and Treatment 35 173-186.

Duss S, Andre S, Nicoulaz AL, Fiche M, Bonnefoi H, Brisken C \& Iggo RD 2007 An oestrogen-dependent model of breast cancer created by transformation of normal human mammary epithelial cells. Breast Cancer Research and Treatment 9 R38.

Edwards DP, Weigel NL, Nordeen SK \& Beck CA 1993 Modulators of cellular protein phosphorylation alter the trans-activation function of human progesterone receptor and the biological activity of progesterone antagonists. Breast Cancer Research and Treatment 27 41-56.

Efeyan A, Fabris V, Merani S, Lanari C \& Molinolo A 2004 Establishment of two hormone respponsive mouse mammary carcinoma cell lines derived from a metastatic mammary tumor. Breast Cancer Research and Treatment 83 233-244.

Elizalde PV, Guerra FK, Gravano M, Lanari C, Lippman ME, Charreau EH \& Lupu R 1995 Correlation of TGF-beta 1 expression with medroxyprogesterone acetate responsiveness in mouse mammary adenocarcinomas. Cancer Investigation 13 173-180.

Elizalde PV, Lanari C, Molinolo AA, Guerra FK, Balana ME, Simian M, Iribarren AM \& Charreau EH 1998 Involvement of insulin-like growth factors-I and -II and their receptors in medroxyprogesterone acetate-induced growth of mouse mammary adenocarcinomas. Journal of Steroid Biochemistry and Molecular Biology 67 305-317.

el Etreby MF \& Liang Y 1998 Effect of antiprogestins and tamoxifen on growth inhibition of MCF-7 human breast cancer cells in nude mice. Breast Cancer Research and Treatment 49 109-117.

el Etreby MF, Liang Y, Wrenn RW \& Schoenlein PV 1998 Additive effect of mifepristone and tamoxifen on apoptotic pathways in MCF-7 human breast cancer cells. Breast Cancer Research and Treatment 51 149-168.

Fabris VT, Benavides F, Conti C, Merani S \& Lanari C 2005 Cytogenetic findings, Trp53 mutations, and hormone responsiveness in a medroxyprogesterone acetate induced murine breast cancer model. Cancer Genetics and Cytogenetics 161 130-139.

Faivre EJ \& Lange CA 2007 Progesterone receptors upregulate Wnt-1 to induce epidermal growth factor receptor transactivation and c-Src-dependent sustained activation of Erk1/2 mitogen-activated protein kinase in breast cancer cells. Molecular and Cellular Biology 27 466-480.

Formelli F, Ronchi E \& Di Fronzo G 1985 Effect of medroxyprogesterone acetate on the growth of mouse transplanted tumors: relation with hormone sensitivity. Anticancer Research 5 313-319.

Fuhrmann U, Hess-Stumpp H, Cleve A, Neef G, Schwede W, Hoffmann J, Fritzemeier KH \& Chwalisz K 2000 Synthesis and biological activity of a novel, highly potent progesterone receptor antagonist. Journal of Medicinal Chemistry 43 5010-5016.

Giulianelli S, Cerliani JP, Lamb CA, Fabris VT, Bottino MC, Gorostiaga MA, Novaro V, Gongora A, Baldi A, Molinolo A et al. 2008 Carcinoma-associated fibroblasts activate progesterone receptors and induce hormone independent mammary tumor growth: a role for the FGF2/FGFR-2 axis. International Journal of Cancer 123 2518-2531.

Glass AG, Lacey JV Jr, Carreon JD \& Hoover RN 2007 Breast cancer incidence, 1980-2006: combined roles of menopausal hormone therapy, screening mammography, and estrogen receptor status. Journal of the National Cancer Institute 99 1152-1161.

Goepfert TM, McCarthy M, Kittrell FS, Stephens C, Ullrich RL, Brinkley BR \& Medina D 2000 Progesterone facilitates chromosome instability (aneuploidy) in p53 null normal mammary epithelial cells. FASEB Journal 14 2221-2229.

Greaves P 2007 Histopathology of Preclinical Toxicity Studies. New York: Academic Press, Elsevier.

Helguero LA, Lamb C, Molinolo AA \& Lanari C $2003 a$ Evidence for two progesterone receptor binding sites in murine mammary carcinomas. Journal of Steroid Biochemistry and Molecular Biology 84 9-14.

Helguero LA, Viegas M, Asaithamby A, Shyamala G, Lanari C \& Molinolo AA $2003 b$ Progesterone receptor expression in medroxyprogesterone acetate-induced murine mammary carcinomas and response to endocrine treatment. Breast Cancer Research and Treatment 79 379-390.

Hernandez FJ, Fernandez BB, Chertack M \& Gage PA 1975 Feline mammary carcinoma and progestogens. Feline Practice 5 45-48.

Hoffmann J \& Sommer A 2005 Steroid hormone receptors as targets for the therapy of breast and prostate cancer recent advances, mechanisms of resistance, and new approaches. Journal of Steroid Biochemistry and Molecular Biology 93 191-200.

Hopp TA, Weiss HL, Hilsenbeck SG, Cui Y, Allred DC, Horwitz KB \& Fuqua SA 2004 Breast cancer patients with 
progesterone receptor PR-A-rich tumors have poorer disease-free survival rates. Clinical Cancer Research 10 2751-2760.

Horwitz KB 1985 The antiprogestin RU38 486: receptormediated progestin versus antiprogestin actions screened in estrogen-insensitive T47Dco human breast cancer cells. Endocrinology 116 2236-2245.

Horwitz KB 1992 The molecular biology of RU486. Is there a role for antiprogestins in the treatment of breast cancer? Endocrine Reviews 13 146-163.

Horwitz KB \& Sartorius CA 2008 Progestins in hormone replacement therapies reactivate cancer stem cells in women with preexisting breast cancers: a hypothesis. Journal of Clinical Endocrinology and Metabolism 93 3295-3298.

Hu Z, Fan C, Oh DS, Marron JS, He X, Qaqish BF, Livasy C, Carey LA, Reynolds E, Dressler L et al. 2006 The molecular portraits of breast tumors are conserved across microarray platforms. BMC Genomics 796.

IARC 1994 Tumors of the Mouse. Lyon, France: IARC Scientific Publications.

IARC Working Group 1979 IARC Monographs on the Evaluation of Carcinogenic Risk to Humans - Sex Hormones (II). Lyon, France: IARC Scientific Publications, World Health Organization.

IARC Working Group 1999 IARC Monographs on the Evaluation of Carcinogenic Risk to Humans - Hormonal Contraception and Post-menopausal Hormonal Therapy. Lyon, France: IARC Scientific Publications, World Health Organization.

IARC Working Group 2007 IARC Monographs on the Evaluation of Carcinogenic Risk to Humans - Combined Estrogen-Progestogen Contraceptives and Combined Estrogen-Progestogen Menopausal Therapy. Lyon, France: IARC Scientific Publications, World Health Organization.

Jabara AG 1967 Effects of progesterone on 9,10-dimethyl1,2-benzanthracene-induced mammary tumours in Sprague-Dawley rats. British Journal of Cancer 21 418-429.

Jabara AG, Toyne PH \& Harcourt AG 1973 Effects of time and duration of progesterone administration on mammary tumours induced by 7,12-dimethylbenz(a)anthracene in Sprague-Dawley rats. British Journal of Cancer 27 63-71.

Jordan VC 2008 The 38th David A. Karnofsky lecture: the paradoxical actions of estrogen in breast cancer survival or death? Journal of Clinical Oncology 26 3073-3082.

Jordan VC \& Brodie AM 2007 Development and evolution of therapies targeted to the estrogen receptor for the treatment and prevention of breast cancer. Steroids 72 7-25.

Kariagina A, Aupperlee MD \& Haslam SZ 2008 Progesterone receptor isoform functions in normal breast development and breast cancer. Critical Reviews in Eukaryotic Gene Expression 18 11-33.
Klijn JG, de Jong FH, Bakker GH, Lamberts SW, Rodenburg CJ \& Alexieva-Figusch J 1989 Antiprogestins, a new form of endocrine therapy for human breast cancer. Cancer Research 49 2851-2856.

Klijn JG, Setyono-Han B, Sander HJ, Lamberts SW, de Jong FH, Deckers GH \& Foekens JA 1994 Pre-clinical and clinical treatment of breast cancer with antiprogestins. Human Reproduction 9 181-189.

Klijn JG, Setyono-Han B, Bontenbal M, Seynaeve C \& Foekens J 1996 Novel endocrine therapies in breast cancer. Acta Oncologica 35 30-37.

Klijn JG, Setyono-Han B \& Foekens JA 2000 Progesterone antagonists and progesterone receptor modulators in the treatment of breast cancer. Steroids $\mathbf{6 5} 825-830$.

Kordon EC 2008 MMTV-induced pregnancy-dependent mammary tumors: early history and new perspectives. Journal of Mammary Gland Biology and Neoplasia 13 289-297.

Kordon E, Lanari C, Meiss R, Charreau E \& Pasqualini CD 1990 Hormone dependence of a mouse mammary tumor line induced in vivo by medroxyprogesterone acetate. Breast Cancer Research and Treatment 17 33-43.

Kordon E, Lanari C, Molinolo AA, Elizalde PV, Charreau EH \& Dosne Pasqualini C 1991 Estrogen inhibition of MPA-induced mouse mammary tumor transplants. International Journal of Cancer 49 900-905.

Kordon EC, Molinolo AA, Pasqualini CD, Charreau EH, Pazos P, Dran G \& Lanari C 1993 Progesterone induction of mammary carcinomas in BALB/c female mice. Correlation between progestin dependence and morphology. Breast Cancer Research and Treatment 28 29-39.

Kordon EC, Guerra F, Molinolo AA, Elizalde P, Charreau EH, Pasqualini CD, Montecchia F, Pazos P, Dran G \& Lanari C 1994 Effect of sialoadenectomy on medroxyprogesterone-acetate-induced mammary carcinogenesis in BALB/c mice. Correlation between histology and epidermal-growth-factor receptor content. International Journal of Cancer 59 196-203.

Labriola L, Salatino M, Proietti CJ, Pecci A, Coso OA, Kornblihtt AR, Charreau EH \& Elizalde PV 2003 Heregulin induces transcriptional activation of the progesterone receptor by a mechanism that requires functional ErbB-2 and mitogen-activated protein kinase activation in breast cancer cells. Molecular and Cellular Biology 23 1095-1111.

Lacroix M, Toillon RA \& Leclercq G 2006 p53 and breast cancer, an update. Endocrine-Related Cancer 13 293-325.

Lamb C, Simian M, Molinolo A, Pazos P \& Lanari C 1999 Regulation of cell growth of a progestin-dependent murine mammary carcinoma in vitro: progesterone receptor involvement in serum or growth factor-induced cell proliferation. Journal of Steroid Biochemistry and Molecular Biology 70 133-142. 
Lamb CA, Helguero L, Fabris V, Colombo L, Molinolo A \& Lanari C 2003 Differential effects of raloxifene, tamoxifen and fulvestrant on a murine mammary carcinoma. Breast Cancer Research and Treatment 79 25-35.

Lamb CA, Fabris V, Gorostiaga MA, Helguero LA, Efeyan A, Bottino MC, Simian M, Soldati R, Sanjuan N, Molinolo A et al. $2005 a$ Isolation of a stromal cell line from an early passage of a mouse mammary tumor line: a model for stromal parenchymal interactions. Journal of Cellular Physiology 202 672-682.

Lamb CA, Helguero LA, Giulianelli S, Soldati R, Vanzulli S, Molinolo AA \& Lanari C 2005b Antisense oligonucleotides targeting the progesterone receptor inhibit hormoneindependent breast cancer growth in mice. Inhibition of hormone independent breast cancer growth in mice by antisense oligodeoxynucleotides of progesterone receptors. Breast Cancer Research 7 R1111-R1121.

Lanari A 1983 Effect of progesterone on desmoid tumors (aggressive fibromatosis). New England Journal of Medicine 3091523.

Lanari A, Molinas FC, Castro Rios M \& Paz RA 1978 Effective treatment of several types of fibromatosis with progesterone. Fibrous mediastinitis, desmoid tumors, paraneoplastic fibrosis. Medicina 38 123-132.

Lanari C, Molinolo AA \& Pasqualini CD 1986a Induction of mammary adenocarcinomas by medroxyprogesterone acetate in BALB/c female mice. Cancer Letters $\mathbf{3 3}$ 215-223.

Lanari C, Molinolo AA \& Pasqualini CD $1986 b$ Inhibitory effect of medroxyprogesterone acetate on foreign body tumorigenesis in mice. Journal of the National Cancer Institute 77 157-164.

Lanari C, Kordon E, Molinolo A, Pasqualini CD \& Charreau EH 1989 Mammary adenocarcinomas induced by medroxyprogesterone acetate: hormone dependence and EGF receptors of $\mathrm{BALB} / \mathrm{c}$ in vivo sublines. International Journal of Cancer 43 845-850.

Lanari C, Montecchia MF, Pazos P, Simian M, Vanzulli S, Lamb C \& Molinolo AA 1997 Progestin-induced mammary adenocarcinomas in BALB/c mice. Progression from hormone-dependent to autonomous tumors. Medicina 57 55-69.

Lanari C, Luthy I, Lamb CA, Fabris V, Pagano E, Helguero LA, Sanjuan N, Merani S \& Molinolo AA 2001 Five novel hormone-responsive cell lines derived from murine mammary ductal carcinomas: in vivo and in vitro effects of estrogens and progestins. Cancer Research $\mathbf{6 1}$ 293-302.

Li M, Spitzer E, Zschiesche W, Binas B, Parczyk K \& Grosse R 1995 Antiprogestins inhibit growth and stimulate differentiation in the normal mammary gland. Journal of Cellular Physiology 164 1-8.

Liang Y \& Hyder SM 2005 Proliferation of endothelial and tumor epithelial cells by progestin-induced vascular endothelial growth factor from human breast cancer cells: paracrine and autocrine effects. Endocrinology 146 3632-3641.
Liang Y, Besch-Williford C, Brekken RA \& Hyder SM 2007 Progestin-dependent progression of human breast tumor xenografts: a novel model for evaluating antitumor therapeutics. Cancer Research 67 9929-9936.

Lin X, Yu Y, Zhao H, Zhang Y, Manela J \& Tonetti DA 2006 Overexpression of PKCalpha is required to impart estradiol inhibition and tamoxifen-resistance in a T47D human breast cancer tumor model. Carcinogenesis 27 1538-1546.

Lydon JP, Ge G, Kittrell FS, Medina D \& O'Malley BW 1999 Murine mammary gland carcinogenesis is critically dependent on progesterone receptor function. Cancer Research 59 4276-4284.

Michna H, Schneider MR, Nishino Y \& el Etreby MF 1989a Antitumor activity of the antiprogestins ZK 98.299 and RU 38.486 in hormone dependent rat and mouse mammary tumors: mechanistic studies. Breast Cancer Research and Treatment 14 275-288.

Michna H, Schneider MR, Nishino Y \& el Etreby MF $1989 b$ The antitumor mechanism of progesterone antagonists is a receptor mediated antiproliferative effect by induction of terminal cell death. Journal of Steroid Biochemistry 34 447-453.

Michna H, Gehring S, Kuhnel W, Nishino Y \& Schneider MR $1992 a$ The antitumor potency of progesterone antagonists is due to their differentiation potential. Journal of Steroid Biochemistry and Molecular Biology 43 203-210.

Michna H, Nishino Y, Neef G, McGuire WL \& Schneider MR $1992 b$ Progesterone antagonists: tumor-inhibiting potential and mechanism of action. Journal of Steroid Biochemistry and Molecular Biology 41 339-348.

Misdorp W 1991 Progestagens and mammary tumours in dogs and cats. Acta Endocrinologica 125 27-31.

Molinolo AA, Lanari C, Charreau EH, Sanjuan N \& Pasqualini CD 1987 Mouse mammary tumors induced by medroxyprogesterone acetate: immunohistochemistry and hormonal receptors. Journal of the National Cancer Institute 79 1341-1350.

Molinolo AA, Pazos P, Montecchia MF, Kordon E, Dran G, Guerra F, Elizalde P, Luthy I, Charreau EH, Pasqualini CD et al. 1996 Pathogenesis of ductal and lobular progestininduced mammary carcinomas in BALB/c mice. In Hormonal Carcinogenesis, vol II, pp 141-147. Eds JJ Li, SA Li, J Gustafsson, S Nandi \& LI Sekely, New York: Springer-Verlag.

Molinolo A, Simian M, Vanzulli S, Pazos P, Lamb C, Montecchia F \& Lanari C 1998 Involvement of EGF in medroxyprogesterone acetate (MPA)-induced mammary gland hyperplasia and its role in MPA-induced mammary tumors in BALB/c mice. Cancer Letters 126 49-57.

Montecchia MF, Lamb C, Molinolo AA, Luthy IA, Pazos P, Charreau E, Vanzulli S \& Lanari C 1999a Progesterone receptor involvement in independent tumor growth in MPA-induced murine mammary adenocarcinomas. Journal of Steroid Biochemistry and Molecular Biology 68 11-21. 
Montecchia MF, Molinolo A \& Lanari C 1999b Reversal of estrogen-resistance in murine mammary adenocarcinomas. Breast Cancer Research and Treatment 54 93-99.

Montero Girard G, Vanzulli SI, Cerliani JP, Bottino MC, Bolado J, Vela J, Becu-Villalobos D, Benavides F, Gutkind S, Patel V et al. 2007 Association of estrogen receptor-alpha and progesterone receptor A expression with hormonal mammary carcinogenesis: role of the host microenvironment. Breast Cancer Research and Treatment 9 R22.

Moore MR 2004 A rationale for inhibiting progesteronerelated pathways to combat breast cancer. Current Cancer Drug Targets 4 183-189.

Mote PA, Bartow S, Tran N \& Clarke CL 2002 Loss of co-ordinate expression of progesterone receptors $\mathrm{A}$ and $\mathrm{B}$ is an early event in breast carcinogenesis. Breast Cancer Research and Treatment 72 163-172.

van Nie R 1964 Growth and regression of hormone-sensitive mammary tumors in mice. Jaarboek van Kankeronderzoek en Kankerbestrijding in Nederland 14 17-20.

Ohi Y \& Yoshida H 1992 Influence of estrogen and progesterone on the induction of mammary carcinomas by 7,12-dimethylbenz(a)anthracene in ovariectomized rats. Virchows Archiv. B, Cell Pathology Including Molecular Pathology 62 365-370.

Pandis N, Heim S, Bardi G, Limon J, Mandahl N \& Mitelman F 1992 Improved technique for short-term culture and cytogenetic analysis of human breast cancer. Genes, Chromosomes and Cancer 5 14-20.

Parkin DM, Bray F, Ferlay J \& Pisani P 2005 Global cancer statistics, 2002. CA: A Cancer Journal for Clinicians 55 74-108.

Pazos P, Lanari C, Meiss R, Charreau EH \& Pasqualini CD 1992 Mammary carcinogenesis induced by $N$-methyl- $N$ nitrosourea (MNU) and medroxyprogesterone acetate (MPA) in BALB/c mice. Breast Cancer Research and Treatment 20 133-138.

Pazos P, Lanari C, Charreau EH \& Molinolo AA 1998 Promoter effect of medroxyprogesterone acetate (MPA) in $N$-methyl- $N$-nitrosourea (MNU) induced mammary tumors in BALB/c mice. Carcinogenesis 19 529-531.

Pazos P, Lanari C \& Molinolo AA 2001 Protective role of medroxyprogesterone acetate on $N$-methyl- $N$-nitrosoureainduced lymphomas in BALB/c female mice. Leukemia Research 25 165-167.

Poole AJ, Li Y, Kim Y, Lin SC, Lee WH \& Lee EY 2006 Prevention of Brcal-mediated mammary tumorigenesis in mice by a progesterone antagonist. Science $\mathbf{3 1 4}$ 1467-1470.

Proia DA \& Kuperwasser C 2006 Reconstruction of human mammary tissues in a mouse model. Nature Protocols 1 206-214.

Rehm D \& Liebelt AG 1996 Nonneoplastic and neoplastic lesions of the mammary gland. In Pathobiology of the Aging Mouse, p 505. Eds U Mohr, CC Dungworth, CC
Capen, WW Carlton, JP Sundberg \& JM Ward. Washington, DC: International Life Sciences Institute, ILSI Press.

Rivas MA, Carnevale RP, Proietti CJ, Rosemblit C, Beguelin W, Salatino M, Charreau EH, Frahm I, Sapia S, Brouckaert $\mathrm{P}$ et al. 2008 TNF alpha acting on TNFR1 promotes breast cancer growth via p42/P44 MAPK, JNK, Akt and NF-kappa B-dependent pathways. Experimental Cell Research 314 509-529.

Russo IH, Gimotty P, Dupuis M \& Russo J 1989 Effect of medroxyprogesterone acetate on the response of the rat mammary gland to carcinogenesis. British Journal of Cancer 59 210-216.

Salatino M, Labriola L, Schillaci R, Charreau EH \& Elizalde PV 2001 Mechanisms of cell cycle arrest in response to TGF-beta in progestin-dependent and -independent growth of mammary tumors. Experimental Cell Research 265 152-166.

Salatino M, Schillaci R, Proietti CJ, Carnevale R, Frahm I, Molinolo AA, Iribarren A, Charreau EH \& Elizalde PV 2004 Inhibition of in vivo breast cancer growth by antisense oligodeoxynucleotides to type I insulin-like growth factor receptor mRNA involves inactivation of ErbBs, PI-3K/Akt and p42/p44 MAPK signaling pathways but not modulation of progesterone receptor activity. Oncogene 23 5161-5174.

Sass B \& Dunn TB 1979 Classification of mouse mammary tumors in Dunn's miscellaneous group including recently reported types. Journal of the National Cancer Institute 62 1287-1293.

Schneider MR, Michna H, Nishino Y \& el Etreby MF 1989 Antitumor activity of the progesterone antagonists ZK 98.299 and RU 38.486 in the hormone-dependent MXT mammary tumor model of the mouse and the DMBA- and the MNU-induced mammary tumor models of the rat.

European Journal of Cancer and Clinical Oncology 25 691-701.

Schneider MR, Michna H, Habenicht UF, Nishino Y, Grill HJ \& Pollow K 1992 The tumour-inhibiting potential of the progesterone antagonist Onapristone in the human mammary carcinoma T61 in nude mice. Journal of Cancer Research and Clinical Oncology 118 187-189.

Seely JC \& Boorman GA 1999 Mammary gland and specialized sebaceous glands (Zymbal, Preputial, Clitoral, Anal). In Pathology of the Mouse. Reference and Atlas, $\mathrm{p}$ 699. Eds RR Maronpot, GA Boorman \& BW Gaul. Vienna, IL: Cache River Press.

Shafie SM 1980 Estrogen and the growth of breast cancer: new evidence suggests indirect action. Science 209 701-702.

Shi YE, Liu YE, Lippman ME \& Dickson RB 1994 Progestins and antiprogestins in mammary tumour growth and metastasis. Human Reproduction 9 162-173.

Shipitsin M, Campbell LL, Argani P, Weremowicz S, Bloushtain-Qimron N, Yao J, Nikolskaya T, Serebryiskaya T, Beroukhim R, Hu M et al. 2007 Molecular definition of breast tumor heterogeneity. Cancer Cell 11 259-273. 
Simian M, Molinolo A \& Lanari C 2006 Involvement of matrix metalloproteinase activity in hormone-induced mammary tumor regression. American Journal of Pathology 168 270-279.

Simian M, Manzur T, Rodriguez V, de Kier Joffe EB \& Klein S 2008 A spontaneous estrogen dependent, tamoxifen sensitive mouse mammary tumor: a new model system to study hormone-responsiveness in immune competent mice. Breast Cancer Research and Treatment 113 1-8.

Sluyser M \& Van Nie R 1974 Estrogen receptor content and hormone-responsive growth of mouse mammary tumors. Cancer Research 34 3253-3257.

Vanzulli S, Efeyan A, Benavides F, Helguero LA, Peters G, Shen J, Conti CJ, Lanari C \& Molinolo A 2002 p21, p27 and $\mathrm{p} 53$ in estrogen and antiprogestin-induced tumor regression of experimental mouse mammary ductal carcinomas. Carcinogenesis 23 749-758.

Vanzulli SI, Soldati R, Meiss R, Colombo L, Molinolo AA \& Lanari C 2005 Estrogen or antiprogestin treatment induces complete regression of pulmonary and axillary metastases in an experimental model of breast cancer progression. Carcinogenesis 26 1055-1063.

Vargo-Gogola T \& Rosen JM 2007 Modelling breast cancer: one size does not fit all. Nature Reviews. Cancer 7 659-672.

Vermeulen M, Pazos P, Lanari C, Molinolo A, Gamberale R, Geffner JR \& Giordano M 2001 Medroxyprogesterone acetate enhances in vivo and in vitro antibody production. Immunology 104 80-86.

Viegas MH, Salatino M, Goin M, Peters G, Labriola L, Costa DC, Lanari C, Charreau EH \& Elizalde PV 1999 Differential expression of and responsiveness to transforming growth factor-beta (TGF-beta) isoforms in hormone-dependent and independent lines of mouse mammary tumors. Cancer Detection and Prevention 23 375-386.
Vollmer G, Michna H, Ebert K \& Knuppen R 1992 Downregulation of tenascin expression by antiprogestins during terminal differentiation of rat mammary tumors. Cancer Research 52 4642-4648.

Wang Z, Zhang X, Shen P, Loggie BW, Chang Y \& Deuel TF 2006 A variant of estrogen receptor- $\alpha$, hER- $\alpha 36$ : transduction of estrogen- and antiestrogen-dependent membrane-initiated mitogenic signaling. PNAS 103 9063-9068.

Wargon V, Helguero LA, Bolado J, Rojas P, Novaro V, Molinolo A \& Lanari C 2008 Reversal of antiprogestin resistance and progesterone receptor isoform ratio in acquired resistant mammary carcinomas. Breast Cancer Research and Treatment [in press].

Watson CS, Medina D \& Clark JH 1979 Characterization and estrogen stimulation of cytoplasmic progesterone receptor in the ovarian-dependent MXT-3590 mammary tumor line. Cancer Research 39 4098-4104.

Wiehle RD, Christov K \& Mehta R 2007 Anti-progestins suppress the growth of established tumors induced by 7,12-dimethylbenz(a)anthracene: comparison between RU486 and a new 21-substituted-19-nor-progestin. Oncology Reports 18 167-174.

Women's Health I 2002 Risks and benefits of estrogen plus progestin in healthy postmenopausal women: principal results from the Women's Health Initiative randomized controlled trial. Journal of the American Medical Association 288 321-333.

Yao K, Lee ES, Bentrem DJ, England G, Schafer JI, O'Regan RM \& Jordan VC 2000 Antitumor action of physiological estradiol on tamoxifen-stimulated breast tumors grown in athymic mice. Clinical Cancer Research 6 2028-2036.

Young S 1961 Induction of mammary carcinoma in hypophysectomized rats treated with 3-methylcholanthrene, oestradiol-17 beta, progesterone and growth hormone. Nature 190 356-357. 